\author{
Antoni Torres \\ Matteo Bassetti \\ Jan Bakker
}

\section{Hospitalized patients at risk of dying: an Intensive Care Medicine call for papers}

Received: 12 September 2015

Accepted: 6 October 2015

Published online: 22 October 2015

(C) Springer-Verlag Berlin Heidelberg and ESICM 2015

\section{A. Torres $(\bowtie)$}

Department of Pulmonary Medicine, Hospital Clinic of Barcelona, University of Barcelona, CIBERES, IDIBAPS, Barcelona, Spain e-mail: ATORRES@clinic.ub.es

\section{Bassetti}

Division of Infectious Diseases, Santa Maria della Misericordia University Hospital, Udine, Italy

\section{J. Bakker}

Erasmus MC University Medical Center, Rotterdam, Netherlands

\section{J. Bakker}

Department of Pulmonology and Critical Care, Columbia University College of Physicians and Surgeons, New York, USA

\section{J. Bakker}

Department of Intensive Care, Pontificia Universidad Católica de Chile, Santiago, Chile

Critical care medicine is an important and inseparable part of modern medical provision. Intensive care units (ICUs), although costly, are an essential element in the delivery of critical care. ICUs are characterized by hi-tech monitoring capabilities as well as increased density of medical and nursing staff compared with general wards or intermediate-care units. However, not all patients for whom ICU admission is indicated are actually admitted to ICU. There are several reasons for this inadequate delivery of care, including [1] lack of sufficient resources to create enough ICU beds and [2] failure of the treatment team outside the ICU to recognize the severity of the disease or the risk of deterioration of a currently stable situation.

With regard to the first point, because not all patients require the use of all resources available in the ICU many hospitals in Europe have created intermediate-care units. These units typically provide more intensive monitoring and patient management than general wards, with higher nurse-patient ratios. These units have been implemented in Europe in the past 10 years; however, a debate is still ongoing [1] about their specific location and organization. The existence of these units is a solution for postoperative monitoring, for patients with single-organ failure, and for those at risk of deterioration during the evolution of their disease.

The second point is particularly important since there is a population, difficult to recognize, that could benefit from ICU admission. Recognition of patients that might need ICU care after hospital admission is not easy and requires validated tools. One illustrative example is severe community-acquired pneumonia, which can usually be detected in the emergency department (ED) using standard criteria [2]. When there is a delay in admitting these patients to the ICU, mortality doubles (50\%) [3]. Possession of tools to monitor patients at risk is extremely important. Renaud and colleagues [4] developed the REA-ICU index, based on data obtained from four prospective multicenter studies in adults with pneumonia (two from North America and two from Europe). Of the 6560 patients included in the study, $303(4.6 \%)$ had no clear indication for ICU admission at presentation but required intensive care in the following 3 days. The authors developed a score comprising 11 variables enabling stratification of patients into four classes of risk for ICU admission on days 1 to 3 (risk increasing from 0.7 to $31 \%$ ). An approach like this may help ED physicians and intensivists in the decision to admit patients to ICU or intermediate-care units. 
Table 1 Patients outside the ICU that could benefit from ICU admission

1. Patients in intermediate-care units who may need intensive care

2. Stable patients admitted to the Emergency Department or a general ward with risk factors that may lead to deterioration

3. Patients assessed as low risk preoperatively patients who may deteriorate postoperatively

4. Patients receiving poor-quality care that may result in the need for intensive care

5. Patients with do not resuscitate orders and end-of-life patients who may be helped by transient palliative intensive care

Despite adequate preoperative assessment of risk, postoperative patients can develop unpredicted complications requiring ICU admission. In these patients (both trauma and pre-/postoperative) a relatively simple score has been validated for early detection of risk for severe morbidity and mortality $[5,6]$. However, these scoring systems detect problems that already exist. So alongside early detection of a deteriorating system, predicting the high likelihood that this will occur in the near future is especially interesting. The latter might not only result in better outcomes but also improve efficiency of care.

Another point related to potential deterioration of patients that initially do not need intensive care is a poor standard of care. This is even more important as it is amenable to medical intervention. Studies on quality of care improvements and scoring systems to assess quality of care that might result in more timely admission of patients to the ICU could thus have a great impact.

Finally, patients with do-not-resuscitate (DNR) orders or end-of-life status constitute an important population that would benefit from ICU admission to receive transient and palliative specialized intensive care [7].

Intensive care outside the ICU is a very broad field (Table 1). Recently, Intensive Care Medicine launched a call for papers on perioperative critical care [8]. Now, we are launching a call for manuscripts on the topic of hospitalized patients at risk of dying. This new call is aimed at both medical and surgical researchers and is open to all specialties. We feel that Intensive Care Medicine is an excellent setting and opportunity for this type of article. We can fast-track these manuscripts, with rapid and fair peer review. We hope that this call will receive many positive responses.

\section{Compliance with ethical standards}

Conflicts of interest A. T. serves on scientific advisory boards for AstraZeneca, Bayer, Basilea, and Roche. M. B. serves on scientific advisory boards for AstraZeneca, Bayer, Cubist, Pfizer Inc., MSD, Tetraphase, and Astellas Pharma Inc. and has received funding for travel or speaker honoraria from Algorithm, Angelini, Astellas Pharma Inc., AstraZeneca, Cubist, Pfizer, MSD, Gilead Sciences, Novartis, Ranbaxy, and Teva. J. B. declares that no conflicts of interest exist.

\section{References}

1. Vincent JL, Rubenfeld GD (2015) Does intermediate care improve patient outcomes or reduce costs? Crit Care $19: 89$

2. Mandell LA, Wunderink RG, Anzueto A, Bartlett JG, Campbell GD, Dean NC, Dowell SF, File TM Jr, Musher DM, Niederman MS, Torres A, Whitney CG, Infectious Diseases Society of America (2007) American Thoracic Society Infectious Diseases Society of America/ American Thoracic Society consensus guidelines on the management of community-acquired pneumonia in adults. Clin Infect Dis 44(Suppl 2):S27S72

3. Phua J, Ngergn Lim TK (2010) The impact of delay in intensive care unit admission for community-acquired pneumonia. Eur Respir J 36:826-833
4. Renaud B, Labarère J, Coma E, Santin A, Hayon J, Gurgui M, Camus N, Roupie E, Hémery F, Hervé J, Salloum M, Fine MJ, Brun-Buisson C (2009) Risk stratification of early admission to the intensive-care unit of patients with no major criteria of severe Communityacquired pneumonia: development of an international prediction rule. Crit Care 13(2):R54

5. Gardner-Thorpe J, Love N, Wrightson J, Walsh S, Keeling N (2006) The value of Modified Early Warning Score (MEWS) in surgical in-patients: a prospective observational study. Ann R Coll Surg Engl 88:571-575

6. Smith T, Den Hartog D, Moerman T, Patka P, Van Lieshout EM, Schep NW (2012) Accuracy of an expanded early warning score for patients in general and trauma surgery wards. Br J Surg 99:192-197
7. Nava S, Ferrer M, Esquinas A, Groff P, Cosentini R, Guido D, Lin CH, Cuomo AM, Grassi M (2013) Palliative use of non-invasive ventilation in end-of-life patients with solid tumours: a randomized feasibility trial. Lancet Oncol 14(3):219-227

8. Jaber S, Citerio G, Talmor D (2015) Intensive Care Medicine launches a call for papers on perioperative critical care. Intensive Care Med 41:971-974. doi: 10.1007/s00134-015-3836-8 